\title{
WHATEVER HAPPENED TO SILICON CARBIDE
}

\author{
R. B. Campbel1 \\ West Inghouse Electric Corporation \\ P. 0. Box 10864 \\ Pittaburgh, PA 15236
}

\section{Sumpar:}

silicon carbide has been used extensively as an abrasive, but only in the last twenty-five years has its potential ae $=$ semiconductor been exploited. The rationale for SiC semiconducter devices is their high temperature performance. Rectifiers, field effect transistors, charged particle detectors, and other devices operate efficiently at temperatures about $800^{\circ} \mathrm{K}$.

It is the purpose of this paper to examine the progress made in SiC devices in the 1955-1975 time frame and suggest reasons for the present lack of interest in ils unique material. The data given in this paper has been abstracted from previously published work.

\section{Introduction}

In the last saventy years, considerable use has been made of the abrasive characteristics of silicon carbide (hereafter SIC); however, only recently were its potentialities as a semiconductor exploited. (i-4) It is the purpose of this paper to discuss SiC devices in the 1955-1975 time frame. Since SiC device properties are intimately connected with its material properties, crystal growth and fabrication techniques will also be discussed. Finally, I will suggest reasons it is no longer considered a viable product for exploitation.

The work discussed in this paper was performed at various induatrial and college research laboratories. These prozrams are no longer active, and there are no known plans or interest in 1 ir reactivation.

\section{Physical and Chemical Properties}

Silicon caroide exists in the hexagonal (a) and cubic (B) phases with the a phase occurring in a variety of polytypes. The various forms of SiC have the largest energy gaps found in common semiconductor materials, ranging from $2.39 \mathrm{eV}$ (cubic) to $3.33 \mathrm{eV}$ (2H). The bonding of $\mathrm{Si}$ and $\mathrm{C}$ atoms is basically covalent with about $12 \%$ ionic bonding. The structures are temperature stable below $1800^{\circ} \mathrm{C}$ and thus form a family of semiconductors useful for high temperature electronic devices. Table 1 shows the lattice parameters and energy gap $\left(0^{\circ} \mathrm{K}\right)$ for the cormon polytypes.

Table 1. Laftice Cusenents and tanergy Gap of Comon SiC Polytypes

\begin{tabular}{|c|c|c|}
\hline Structure & $\begin{array}{l}\text { Lettice Pgrmeter: } \\
\text { (A) }\end{array}$ & Enerey $\operatorname{Cap}\left(0^{\circ} x\right)$ \\
\hline $\mathbf{2 7}$ & $=3.09, c=5.040$ & 3.33 \\
\hline$\omega$ & $=-3.09, c=10.05$ & 3.26 \\
\hline 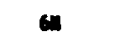 & $=-3.0817, c=15.1183$ & 3.02 \\
\hline 33 & & 3.01 \\
\hline 158 & $-3.079 \cdot c-37.78$ & 2.996 \\
\hline $2 \mathbf{m}$ & $\bullet-3.079 .5-52.86$ & 2.66 \\
\hline 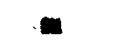 & & $2.80-2.90$ \\
\hline cuble-3c & -0.450 & 2.39 \\
\hline
\end{tabular}

SiC is inert to nearly all laboxatory reagents, and the usual techniques for chemical etchir. 3 employ wolten salt or salt mixtures ( $\mathrm{NaOH}, \mathrm{Na}_{2} \mathrm{O}$, horax) at

temperatures above $600^{\circ} \mathrm{C}$. Electrolytic etchirg, sultable for p-type material and etching with gaseous chlorine near $1000^{\circ} \mathrm{C}$, may also be used.

The physica: 1..-dness and chemical inertness inpose great restraints on device iabrication techniques. Although SIC technology has progressed along the same lines as that of stlicon, many techniques had to be developed which were peculfar to SiC and which inevitably made the fabrication more difficult and expensive.

\section{Methods of Preparation}

The oldest and pernaps the best known method of SiC crystal growth is the sublimation method. This technique uses the vaporization of a SiC charge at about $2500^{\circ} \mathrm{z}$ into a cooler cavity with subsequent condensation. Initially the charge formed its own cavity, but more uniform crystals are grown when a thin graphite cylinder is used in the center of the charge. This thin cylinder also reduces the number of nucleations so that fewer but more perfect crystals are grown. The crystals are grown as thin hexagonal platelets, perpendicular to the growth cavity. Doped crystals, containing $p-n$ junctions, can be prepared oy adding proper dopants to the ambient during griwth. The power rectifiers, to be described later, were prepared by this method.

Other methods of crystal growth are epitaxy, traveling solvent and solution growth.

The hexagonal a phase is grown epitaxially from $1725^{\circ}$ to $1775^{\circ} \mathrm{C}$ with the cubic phase being grown from $1660^{\circ} \mathrm{C}$ to $1700^{\circ} \mathrm{C}$. In both cases, equal molar percentages of $\mathrm{CCl}_{4}$ and $\mathrm{SiCl}_{4}$ are used. Polished and etched SiC crystal were generally used as substrates although Ryan and co-wcrkers at Ai- Force Cambridge Research Laboratory have investigated the growth of SiC onto carbon substrates using the hydrogen reduction of methyltrichlorosilane $\left(\mathrm{CH}_{3} \mathrm{SiCl}_{3}\right)$ (called the vapor-

1iquid-solid growth). At $1500^{\circ} \mathrm{C}, a-5 i \mathrm{C}$ whiskers on the order of $5 \mathrm{~mm}$ long by 1 man diameter were grown. These whiskers were of the relatively rate $2 \mathrm{H}$ polytype.

Sic crystals have been grown together, and $p-n$ junctions formed by passing a heat zone through two SiC crystals separated by a solvent metal (traveling solvent). The temperature gradient across the thin solvent zone causes dissolution at both solvent-solid interfaces. However, the equilibrium solubility of SiC in the solvent is greater at the hotter interface, a concentration gradient is established. The solute, then, will diffuse across the 1iquid zone and precipitate onto the cooler crystal. In this way, two dissinilar conductivity type SiC crystals can be grown together.

In the solution growth technique, a small amount of SIC is dissnlved in molten Si (or in some cases Fe or $\mathrm{Cr}$. As the melt is slowly cooled, the Sic becomes less soiuble; and SIC crystals nucleate and gros in the cructble on prepared graph1te substrates. The grown crystals are normally of the B-phase. Improvements in the crucible geometry and cooling rates have led to 
cublc erystals up to $4 \mathrm{~mm}$ across and $0.1 \mathrm{~mm}$ thick. With the use of pure starting materials and extensive degassing, quite pure crystals can be grown; and electron mobilities of $500 \mathrm{~cm}^{2}$ per volt-sec have been measured.

\section{Device Techniques}

The specific device techniques used will var" from device to device, and it is the purpose of this section to discuss Eabrication methods in a generzl manner. In later sections when thr individual devices are described, any special techniques required will be discussed.

Tice mechanical shaping of a hard crystal such as SiC is generally accomplished by scribing and breaking, lapping and polishing, ultrasonic cutting and atr abrastve cutting. Boron carbide and/or diamond are used for these purposes since they are the only materlals sufficiently hard.

Scr.bing the crystal with a diamons point and breaking it along the scitibe line can also be used. As vill be discussed later, a number of fieli ef fect transistors were fabricated on a single crystal; and these transisturs were separated by scribing. Obviously this is best carried out on a scribing machine.

A11 of these mechanical shaping operations inevitably leave surface and bulk damage in the crystal. Some studies have indicated tnat the damage may propagate into the crystal by microcracks to a depth of tens of microns. For optimum device performance this damage must be removed, e.g., by chemical etching.

The etching of $\mathrm{SiC}$ using molten salts has been described in detail by Faust in 1959. In his paper, Faust describes the side of the SiC crystal which etches in a rough "wormy" pattern using molten salt on the carbon side and the side where the etch is smooth as the silicon side. This data has also been confirmed by Brack in 1965, using X-ray techniques.

Chang and co-workers studied the diffusion of aluminum into $\mathrm{SiC}$ from $1750^{\circ} \mathrm{C}$ to $2100^{\circ} \mathrm{C}$, using both closed tube and open tube flowing gas techniques. Since the SiC crystals will decompose at these temperatures, it was necessary to provide an equilibrium pressure of $\mathrm{S} i$ and $\mathrm{C}$ vapor species arourc the crystals during the diffusion process. Griffiths 121965 and Vodakov et al in 1966 reported further experiments using similar techniques. The activation energy for the diffusion of aluminum into sic found in these three studies agreed within $5 \%(-4.8 \mathrm{eV})$

Further refinements in unpublished work by Canepa and koberts of the Westinghouse R\&D Center resillting in junction depletion widths up to $25 \mu_{\text {in }}$ were obtained sing a combination of infinite source and finite source diffuston techniques.

Another technique is to use gaseous etching, e.g., $\mathrm{Cl}_{2}$ at $950^{\circ} \mathrm{C}$ to $1050^{\circ} \mathrm{C}$ (Thibault) or $\mathrm{Cl}_{2}+\mathrm{O}_{2}$ at $1000^{\circ} \mathrm{C}$ (Smith and Chang).

\section{Characteristics of S1C Devices}

Figure 1 shows the reverse characteristics of the IV properties of a SiC rectifler prepared by the grown junction method, operating at one ampere and $30^{\circ} \mathrm{C}$ and $500^{\circ} \mathrm{C}$. The forward voltages of these devices, even at $500^{\circ} \mathrm{C}$, are always larger than 1 volt (half wave average). Thus far, cectiflers operating "n to $10 \mathrm{~A}$ have been fabricated, and specially processed low current devices have exhibited reverse capability of
600 PIV. The reverse characteristic of SiC rectifiers generally show : "solt" breakover, rather than tile avalanche breakdown sometimes noted in silicon. This is generaily attributed to tile carrier generation mecha" am at the junction and to local areas hreaktrig down If ferent voltages, so that the total effect is one or gradually increasing reverse current.

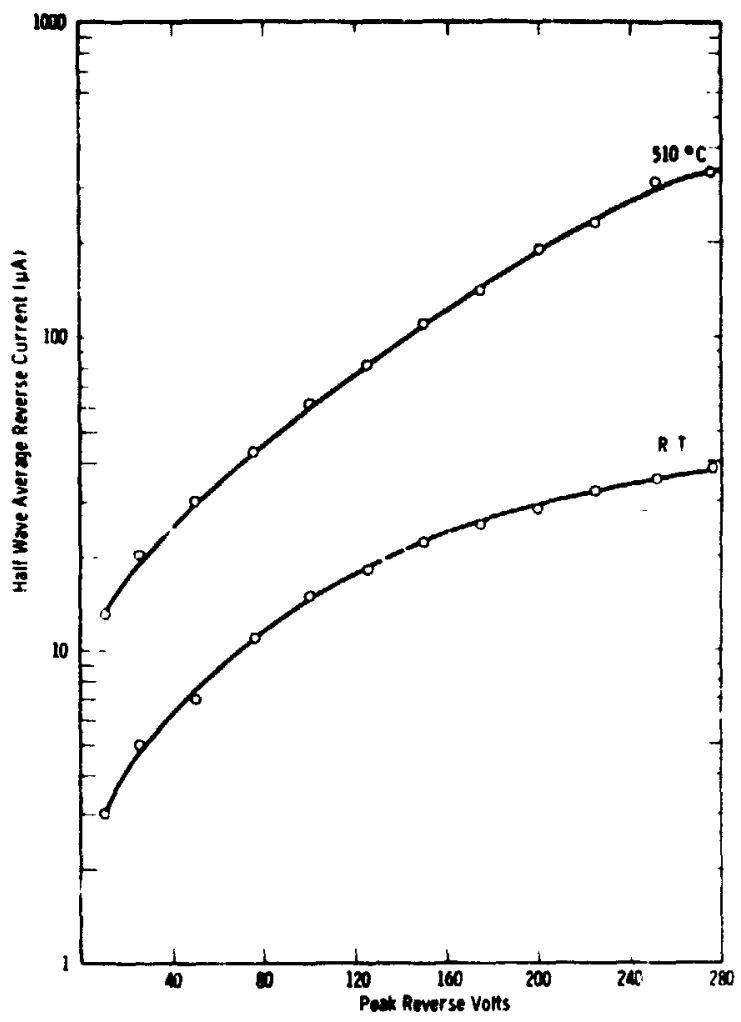

Figure 1. Representative properties of silicon carbide grown junction rectifiers - reverse characteristics

Although very limited life test data have been ob-tained for these grown junction rectifiers, a few devices have been operated at several amperes for up to 200 hours at $500^{\circ} \mathrm{C}$ in air, with no change in electrical characteristics. Devices operating at one ampere and using approximately the same encapsulation have been successfully life tested fur 1000 hours at $500^{\circ} \mathrm{C}$.

The operation of a $p-n$ junction nuclear particle or photon detector depends on the collection of electran-hole pairs produced by the fonizing particle or photon as it passes through the detector. The electron-hole pairs are separated in the junction region, collected, and give rise to a charge or voltage pulse.

Silicon photovoltaic diodes have been developed for the detection of infrared and visible radiation. These diodes exhiblt a shard Jrop in response as the wavelength of the incident light approaches the ultraviolet region with most detectors showing negligible response below $3000 \AA$. This decreasing response is due to the increase in the absorption coefficient with decreasing wavelength. A large absorptiun coefificlent indicates nearly all the light will be atsorbed at the surface of the device, and electron-hole palrs generated may be at a great distance from the $p-n$ junction. Thus, surface ef fects, such as carrier recombtnation, will decrease the response of the detector. 
SiC, with a band gap near $3.0 \mathrm{eV}$, has an absorntion coefficient several orders of magnitude less than that of $S 1$ at $4000 \AA$, and therefore surface effects would not be so impo:tant. Detectors have been prepared from SIC, and these devices were found to have a spectral response which were a maxinum in the ultraviolet region and which could be shifted by varying the junction depth.

A simple theoretical model was originally derived by Chang and Campbell which quantitatively explained the dependence of the peak wavelength on the junction depth and the depletion width of the diode. Considered in this model were the wavelength and temperature dependences of the absorption coefficient in SIC below the band edge. An approximation was made that at the peak response wavelens, the total number of electron-hole pairs generated in the depletion layer is a maximum for a given intensity of transmitted radiation at the surface

Figure 2 shows the variation of peak response wavelength calculated from this model. The curves are siown for values of the effecive depletion width (w) from $w=1$ micron to $w=10$ microns.

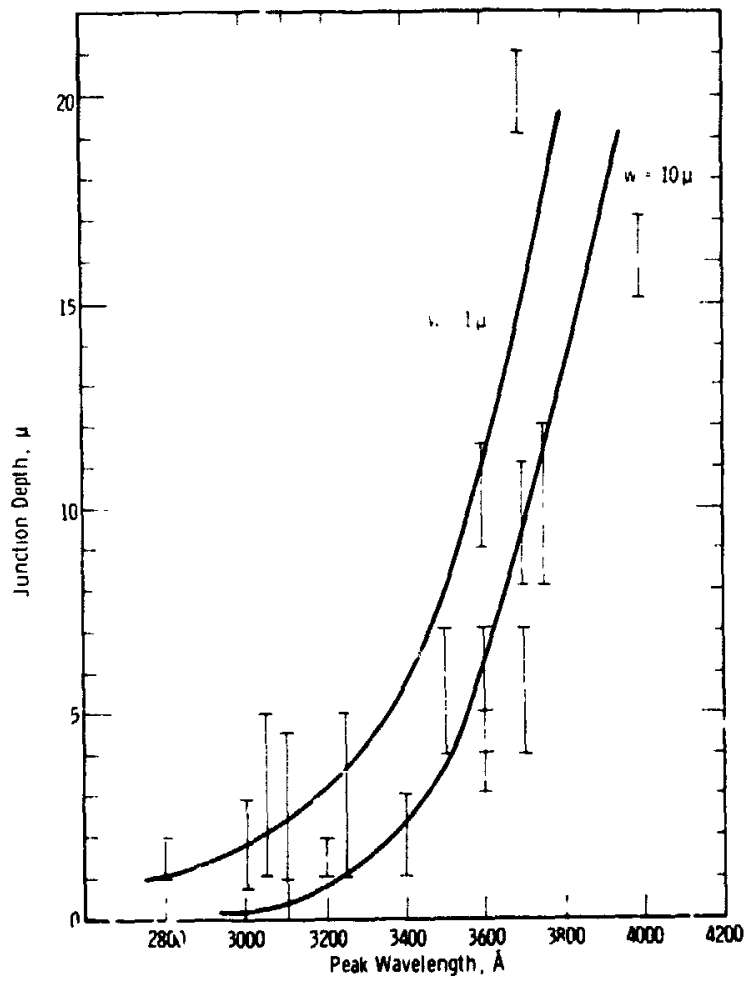

Figure 2. Peak spectral response of silicon carbide junction diode as a function of junction depth (after Campbell and Chang)

In addition to these photon detectors, SiC d tode structures, spectally prepared with graded junctions, have heen ised to detect alpua particles; and with the addition of a conversion layer, thermal neutrons have been counted.

The fission products of $U-235$ irradiated with thurmal neutrons are not unique but have a distributior. with two peaks occurring in the fisslon product mass distribution curve. The total energy liberated 1s $15^{7} \mathrm{MeV}$ with peaks at 66 and $91 \mathrm{MeV}$. Figure 3 shows a comparison of the alpha and fission product spectra for a SiC diode. The fission products spectra are very close to those predlcted from the $\alpha$-particle response taking into account the different distribution in the inildent energy. The SIC diode, which had a peaked a-spectra, also shows a peak fission product spectra: in fact, the 11ssion spectra of the dlode resolves the double peaks.

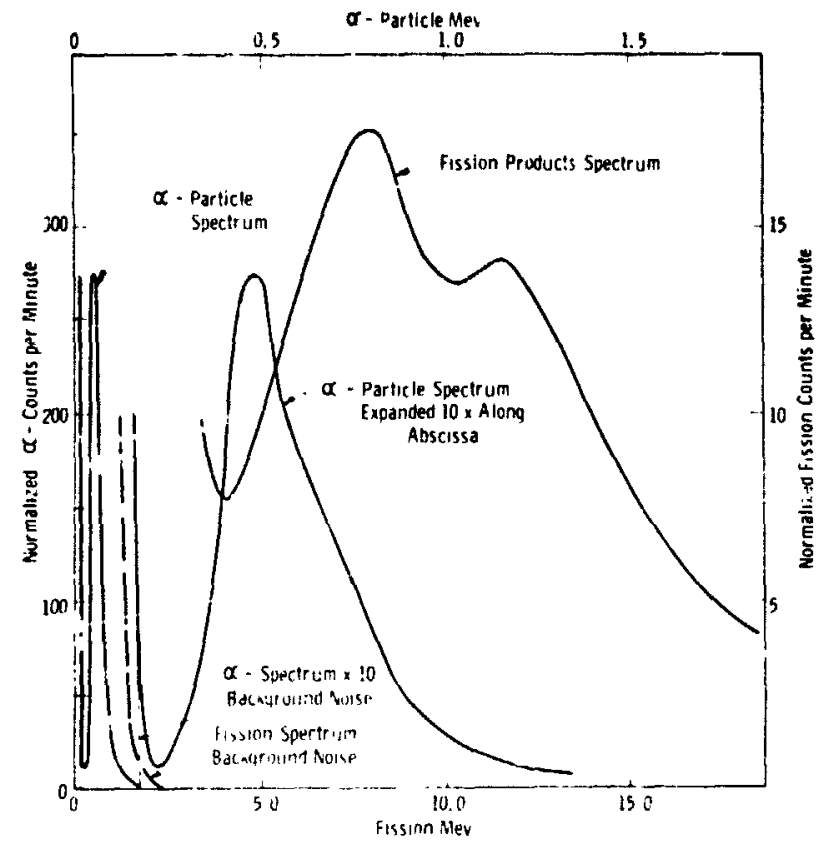

Figure 3. Comparison of alphid particle and fission fragment counting of silicon carbide junction diode (after Canepa et al)

Tunnel diodes in sir can be made by forming a heavily doped alloved junction in either $n$ - or p-type degenerate SiC crystals, using a very fast alloying cycle similar in principle to that originally used to produce Ge tunnel diodes. Degenerate n-type SiC can be grown readily with heavy nitrogen doping. The p-type degeneracy in SIC cannot be established until the uncompr $n s$ ted acceptor level approaches 1020 $10^{21} \mathrm{~cm}^{-3}$, which has not been achieved.

An operable SiC tunnel dilode was reported iy Kutz in 1964. The junction was ormed by alloying $\mathrm{Si}$ in a nitrogen-containing atmosphere to very heavily Aldoped $\alpha$-SiC crystals $\left(4.5 \times 10^{20}-9 \times 10^{20}\right.$ uncompensated acceptors $\mathrm{cm}^{-3}$ ). The highest peak-to-valley current ratio achieved was 1.37 at room temperature, but negative resistance was observed at temperatures as high as $500^{\circ} \mathrm{C}$. The peak voltage is unusually high, approxtrately $0.9 \mathrm{~V}$ and $24^{\circ} \mathrm{C}$. Figure 4 shows the IV characteristics of a SiC tunnel diode at several temperatures.

The channel dimensions and other device dimenstons in a SiC junction gate field effect transistors are quite small due to the low carrier lifetime and correspondingly short diffusion lengths. Thus, the fabrication, of these devices require photollthographic techniques. Using a self-masked diffusion process and gaseous etching (soe Figure 5), Chang et al fabricated

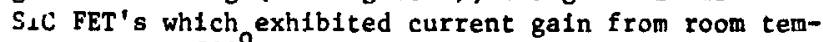
perature to $500^{\circ} \mathrm{C}$.

A silicou carbide thermistor was described by Campsell in 1973. This device takes advantage of the exponential decrease in resistance of a sic function 


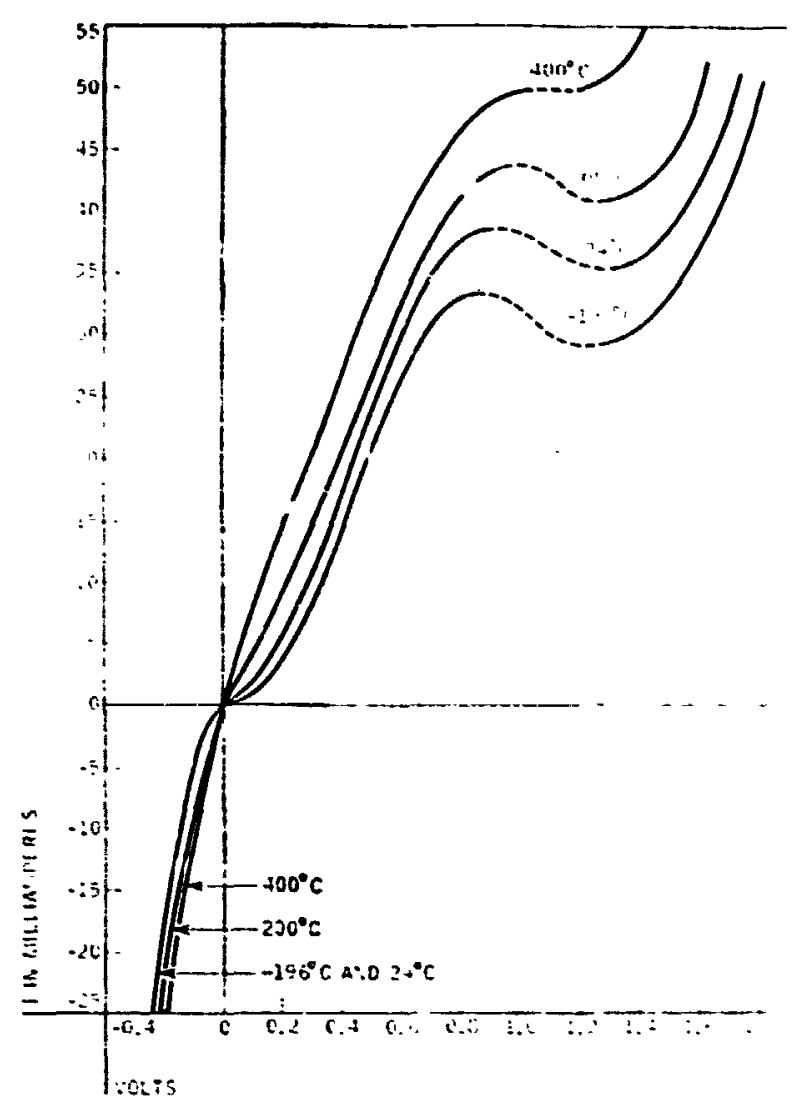

Figurc 4. IV characteristics of silicon carbide tunnel diode from $-196^{\circ} \mathrm{C}$ to $400^{\circ} \mathrm{C}$ (after Rut 2 )

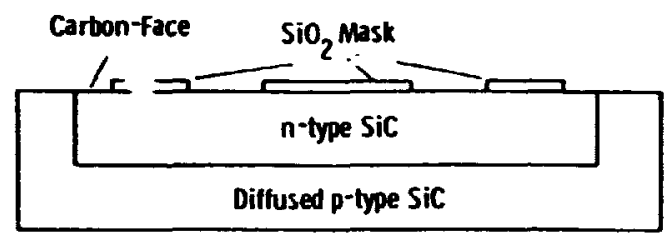

(a) Section view, oxide naskk after photoresist etch

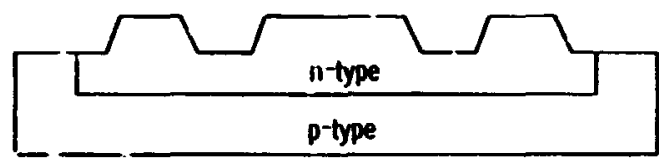

(b) Following $\mathrm{Cl}_{2}{ }^{-\mathrm{O}}$ elch and removal of oxide

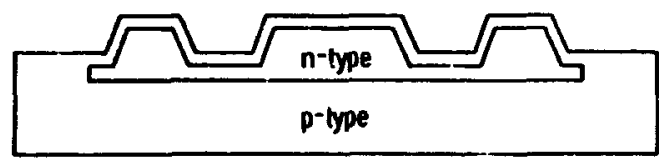

(c) Following second diffusion of p-1,: * mpurity

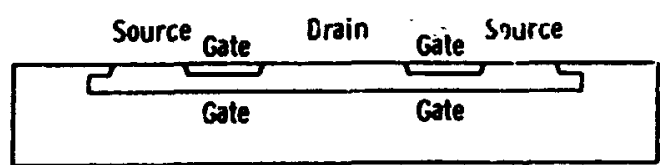

(d) "Self-mask" removed leaving finished structure with temperature. Since this resistance changes by an order of angnitude for every $10 \mathrm{nc}^{\mathrm{C}}$ tcaperacure change, a change of a few tenths of a degree is easily Netecteo. Prototype devices have been operated several thousand hours (with frequent cycling) without degradation.

\section{Conclusions}

Tnus far I have given a brief outline of SiC semiconductor devices and methods for their fabrication. The data given show that SiC devices are feasible and have properties that should be of interest to several high technology fields. The question then arises: Why is there so little interegt in this mat. ria: today, and why are there no SiC devices current] in use?

I believe there are three specific reasons for this. First, in the later 1960's there was a decline in corporate and Government R6D funding due to economic conditions. At this time, Sic had not carved out its niche in the semiconductor device market and thus was a prime candidate for any cutback. A second, somewhat related, cause was the disappearanse of the swall market where SiC devices did have a chance to make an impact. These were high technology areas such as near sun space missions, supersonic an-l nxpersonir aircraft, etc. When these markets disappeared, much if the interest in SiC also disappeared. Finally, the fabrication. techniques for SiC devices (including grow th methods) did not improve appreciably in the twent: years undar question. This lack of progress may :.ave been due to misplaced emphasis in device programs, but the net result was that the fabrication techniques fur Sic devices improved only slightly in this time span.

Now, whcre do we go fron here? I see no viabla market for SiC semiconductor devices in tho near future. Improved $S i$ devices, better insulation, improved circuit design all mitigate against any exiensive use of SiC devices. This mis be viewed as an unfertunate circumstance to many of us who were professionally and emotionally involved with this interesting material for a number of years.

\section{Acknowledgments}

I would like to thank any colleagues for their contributions to the given data. I also wish to thank the tixecutive committee and fellow members of the International Committee on Silicon Carhide for their encouragement.

\section{References}

The following four references contain all the work discussed in this piper.

1. Silficon Carbide, A High Temperature Semiconductor, Pergamon Press, New York, 1960.

2. Silicon Carbide - 1968; Pergamon Press, New York, 1969.

3. Ticon Carbide - 1973; Edited R. C. Marshall, J. ". Faust and C. E. Ryan, Univ. of South CaroIina Press, Columbia, S.C., 1974.

4. Silicon Carbide as a Semiconductor; J. Feitknecht Springer Truets in Modern Physics, Volume 58; Springer-Verlay, Berlin, 1971.

Figure 5. Self-masked difiusion technique 